\title{
Diseño de un ciclo de mejora en el aula para la enseñanza del registro arqueológico
}

\section{Design of a improvement cycle in classroom for teaching the archaeological record}

SEBASTIÁN VARGAS VÁZqUEZ

Universidad de Sevilla

Departamento de Prehistoria y Arqueología

svargas2@us.es,

Orcid: https://orcid.org/0000-0002-6015-412X

DOI: http://dx.doi.org/10.12795/9788447231003.069

Pp.: 1458-1485 


\section{Contexto}

El presente ciclo de mejora docente se aplica en la asignatura Documentación y análisis del registro arqueológico del Master Universitario en Arqueología de la Universidad de Sevilla.

Se trata de una asignatura en la que se ofrece al/la alumno/a los conocimientos necesarios para entender los distintos tipos de entidades arqueológicas, el concepto de yacimiento y el proceso de formación del registro arqueológico. Asimismo, se persigue que los alumnos conozcan las técnicas de documentación del registro arqueológico dentro de los diferentes desarrollos metodológicos de la disciplina, aunque nos centraremos especialmente en la excavación arqueológica.

Para ello, es fundamental que el/la alumno/a conozca bien cuál es la función de un arqueólogo/a y qué persigue, qué es una excavación arqueológica, cuál es su cometido y cómo se desarrolla, cómo se forma el registro arqueológico y cómo se debe afrontar su documentación. En este sentido, conocer los mecanismos y las herramientas para la correcta recogida de datos y la adecuada gestión de la información es clave para entender el desempeño de la actividad arqueológica.

Al uso de las herramientas más tradicionales tales como libro diario, fichas documentales, base de datos, fotografía tradicional, dibujos y desarrollo de planimetría, topografía, etc., el/a alumno/a deberá añadir los conocimientos básicos del funcionamiento y la utilidad de nuevos mecanismos de registro y documentación, tales como la fotogrametría, la fotografía satélite, la fotografía térmica, los mecanismos de prospección geofísica (georradar, magnetometría, entre otras), el escáner láser, etc.

Con todo ello, se persigue crear una base sólida de conocimiento para que el/la alumno/a, sea capaz de diseñar 
la estrategia más factible a la hora de afrontar cualquier tipo de actividad arqueológica, actuando con firmeza y razonamiento crítico en la toma de decisiones. Deberá ser capaz, además, de emitir propuestas sólidas de resultados, así como solventar cualquier tipo de eventualidad.

Para la correcta gestión de la recogida de datos y su análisis, el/la alumno/a debe entender, asimismo, que junto a una actitud segura y responsable, respaldada por unos conocimientos sólidos, el trabajo en equipo y el auxilio o la colaboración con profesionales de otras disciplinas es absolutamente fundamental para el buen desarrollo de la actividad.

\section{Diseño del ciclo de mejora docente}

La asignatura elegida para la aplicación del ciclo de mejora es clave para el desempeño de la actividad arqueológica y una de las más importantes de la disciplina. El registro arqueológico y su correcta documentación y lectura, basada en una adecuada gestión de la información y los datos obtenidos, es fundamental para emitir una propuesta de resultados clara, convincente y rigurosa, que nos ayude a entender el yacimiento arqueológico en toda su extensión.

Aunque la asignatura se imparte en el Master de Arqueología de la US, hay que tener en cuenta que no todos/ as los/as alumnos/as matriculados/as tienen conocimientos sólidos relacionados con la arqueología, algunos/as de ellos/as han cursado el grado en Historia, Historia del Arte, turismo, e incluso otras titulaciones más alejadas y menos afines.

Enfocar la asignatura de un modo seguro para que nadie se sienta desubicado y para que al final todos/as entiendan los conceptos generales que se van a tratar, es una tarea ardua que en este caso vamos a afrontar siguiendo la metodología de enseñanza-aprendizaje recogida en este CIMA.

Ciclos de Mejora en el Aula (2020). Experiencias de Innovación Docente de la US Esta obra se distribuye con la licencia Creative Commons 


\section{Mapa de contenidos}

El diseño del mapa de contenidos ideado para el desempeño del ciclo de mejora docente responde claramente a las necesidades y a la realidad palpable que se percibe en la clase en la que se va a impartir, en la que, como hemos señalado anteriormente, la inmensa mayoría de los/ as estudiantes matriculados no han tenido contacto alguno con la arqueología.

De dicha realidad somos conscientes en la primera toma de contacto con el alumnado y tras el desarrollo de una breve encuesta. El análisis pormenorizado del cuestionario que inmediatamente después pedimos que cumplimenten (formulario inicial), vuelve a remarcar esa realidad y entendemos que no tiene sentido profundizar en el registro arqueológico si los/as estudiantes no tienen antes una idea clara de lo que es la arqueología, que persigue o de cuál es la labor propia del arqueólogo/a.

Teniendo en cuenta todo lo anterior, nos vemos obligado a organizar el mapa de contenido en base a esas premisas, y contemplar contenidos básicos y claves para la materia a impartir y que giran en torno al significado de la arqueología, su fundamento, utilidad y modo de proceder. Asimismo, creemos conveniente profundizar, entre otros asuntos, en la labor y los cometidos del/la propio/a arqueólogo/a, que sin duda alguna es, junto con su equipo, el/la responsable de gestionar, analizar e investigar el registro arqueológico, fundamento y núcleo central de la asignatura.

Todo ello es fundamental para encuadrar la materia y crear cierta cohesión de grupo, de tal modo que nadie se sienta desplazado/a en función a sus conocimientos.

En base a esas premisas, proponemos para afrontar la asignatura el mapa de contenidos y preguntas expresado en la figura 1, donde se agrupan los contenidos conceptuales y actitudinales más destacables.

Ciclos de Mejora en el Aula (2020). Experiencias de Innovación Docente de la US Esta obra se distribuye con la licencia Creative Commons 
Los contenidos conceptuales giran, como ya hemos adelantado, en torno a los conceptos arqueología, arqueólogo, yacimiento arqueológico, registro arqueológico, excavación, remarcados en naranja en el mapa, y con ellos se vinculan otros igualmente fundamentales, como el método estratigráfico, el contexto arqueológico, etc., que en este caso aparecen remarcados en rojo.

Junto a esos contenidos, en el mapa se reflejan una serie de preguntas, remarcadas en celeste, que busca profundizar y cohesionar distintos contenidos.

Por último, el mapa comprende también aquellos contenidos actitudinales, remarcados en azul, que buscan que el/la estudiante entienda la importancia de la tarea que tiene entre manos y que la arqueología es una materia que en su desarrollo va eliminando capas y estratos y que no hay vuelta atrás, por lo que el compromiso, la meticulosidad, la fortaleza y la seguridad en el desarrollo de la actividad y en la toma de decisiones es absolutamente imprescindible y tiene que ser una realidad continua e inexcusable. Al mismo tiempo, esa misma actitud debe manifestarse en la recogida y análisis de datos y materiales, y en el tratamiento de la información, que debe efectuarse de manera rigurosa, continua y ordenada.

La necesidad y la importancia del trabajo en equipo es otro de los contenidos actitudinales fundamentales que deben interiorizar los/las estudiantes, puesto que para el caso que nos ocupa es absolutamente fundamental para el buen desarrollo de la actividad. En este sentido, se debe habituar a trabajar en grupo, a tener en cuenta, respetar y contrastar las ideas emitidas por el resto de compañeros/as, fomentando el debate activo y constructivo ante cualquier problema y eventualidad. Todo ello debe servir, además, para que el grupo, en un ambiente de amistad y de respeto, llegue a acuerdos y emita respuestas 
consensuadas a los problemas que se le vaya presentando; siendo necesario, en este caso, el esfuerzo de todos/as en la toma de decisiones.

Por último, se profundiza en otro contenido actitudinal que intenta poner de relieve la importancia de la colaboración del grupo con otros agentes externos. A partir del mismo, el/la alumno/a tiene que tener muy presente la necesidad de colaborar con otras disciplinas. Y es que la arqueología requiere para su correcto funcionamiento del auxilio de otras materias y disciplinas, por lo que el/la estudiante tiene que entender que no siempre tiene que abarcar cuestiones que se alejan de su materia, intentado actuar como topógrafo, arquitecto, geólogo, geógrafo, físico-químico, etc., sino que más bien debe conocer cuáles son los cometidos generales y las prestaciones que se pueden derivar de esas y muchas otras materias, disciplinas o técnicas, para saber dónde y a quién acudir en cada momento, en función de las necesidades que se generen en el transcurso lógico de la actividad arqueológica, que incluye la gestión, tratamiento y análisis final de los restos. El trabajo en grupo, en este caso, sigue siendo fundamental.

Todo ello se ha intentado reproducir y poner de manifiesto en clase, a través de la cooperación y del trabajo de los/las estudiantes en grupo. Para ello, hemos planteado una serie de tareas que abarcan los contenidos procedimentales contemplados en el CIMA, y que implican el conocimiento, control y buen manejo de la normativa vigente en materia de patrimonio arqueológico, de la metodología y de la práctica arqueológica, a través de simulaciones de actividades arqueológicas a desarrollar por parte de los distintos grupos, marcando y definiendo los pasos para su desarrollo, proponiendo su lectura y la correcta gestión, análisis e interpretación del registro arqueológico.

Ciclos de Mejora en el Aula (2020). Experiencias de Innovación Docente de la US Esta obra se distribuye con la licencia Creative Commons 


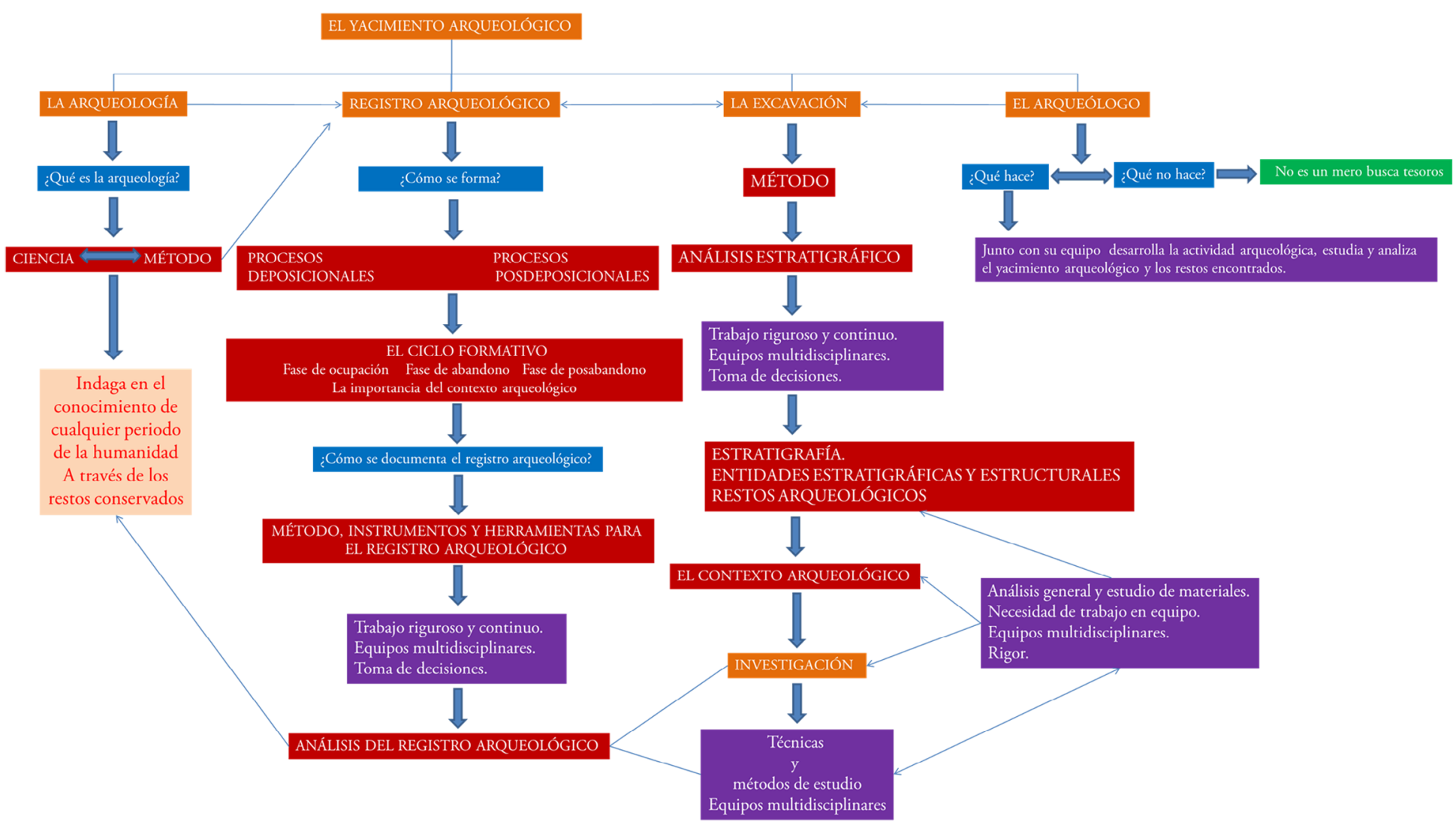

Figura 1. Mapa de contenidos y preguntas

Ciclos de Mejora en el Aula (2020). Experiencias de Innovación Docente de la US (C) Esta obra se distribuye con la licencia Creative Commons cc) Internacional (CC BY-NC-ND 4.0.) 


\section{Modelo metodológico y secuencia de actividades}

El presente ciclo de mejora contempla un profundo cambio metodológico a la hora de impartir docencia. Dicho cambio permite superar el modelo tradicional más extendido, basado en la típica clase magistral de carácter expositivo, o modelo basado en la transmisión (De Alba y Porlán, 2017, 38), en el que el protagonismo recae sobre el/ la docente, para adoptar una nueva metodología de enseñanza-aprendizaje más actual y formativa, que fomenta una mayor implicación y participación del/la estudiante en base al principio de investigación, que permite que éste se sumerja en la materia por medio de la puesta en marcha de problemas, preguntas, casos, proyectos, etc., cuyo desarrollo implique un verdadero desafío para el/la estudiante (De Alba y Porlán, 2017, 45-49).

Con esta nueva metodología, el/la alumno/a se convierte en actor principal, procurando indagar y resolver las cuestiones y actividades plateadas en base a razonamientos lógicos y aplicando un pensamiento crítico y creativo, mientras que el/la docente, que deja paso a esa mayor implicación del alumnado, se convierte en el guía que dirige el camino hacia el conocimiento en torno a la materia que se quiere impartir. Con ello se consigue que los contenidos se asimilen de una manera más amable y segura y que el conocimiento se asiente de un modo mucho más firme y duradero.

En todo ese recorrido, el trabajo en grupo es fundamental, al permitir que el/la alumno/a contraste su propio pensamiento y sus propias ideas, a partir de las opiniones expresadas por sus compañeros/as. Se potencia con ello, una conducta colaborativa que enriquece a la persona y al grupo, y que permite emitir respuestas o afrontar tomas de decisiones de una manera más segura y creativa.

Ciclos de Mejora en el Aula (2020). Experiencias de Innovación Docente de la US Esta obra se distribuye con la licencia Creative Commons 
El cambio, sin embargo, no es simple, todo lo contrario, se vuelve complejo y laborioso, fundamentalmente porque exige tener muy seguro qué es lo que se quiere enseñas y cómo se quiere enseñar, para a continuación seleccionar y relacionar los conceptos más significativos y definitorios de la materia que se quiere impartir. Implica, además, programar y pensar muy bien las distintas clases o sesiones, de tal manera que los/las estudiantes se sientan seguro y no perciban lagunas e incongruencias que les lleve al desánimo.

Desde la propia reflexión personal, debo decir que en esta experiencia tan incipiente en la que me he introducido, he podido comprobar que programar preguntas o generar problemas que en su interior impliquen conocer bien los conceptos generales y específicos de la asignatura, haciéndolos interactuar entre ellos, requiere de un amplio conocimiento y control de aquello que realmente tiene interés en relación con la materia que se quiere impartir. Por otra parte, intentar que los/las estudiantes se acerquen a la realidad a partir de la propuesta de resolución de casos prácticos o de la formulación de supuestos, obliga, igualmente, a una doble tarea, crear un mundo imaginario, lo más cercano posible a la realidad, y resolver sus problemas en función de los conocimientos adquiridos. En este punto, la adecuada programación de las actividades es clave, y la orientación y guía del/la profesor/a es fundamental para resolver dudas y evitar formulaciones banales y simples, y para promover una implicación real por parte de los/las estudiantes. La aplicación de distintos tipos de tareas de contrastes, especialmente aquellas basadas en la resolución de problemas reales, ha sido en todo ese proceso una herramienta clave y fundamental. Para todo ello, hemos seguido las pautas y recomendaciones expresadas en Bain (2007), Finckel (2008) y Porlán (2017).

Ciclos de Mejora en el Aula (2020). Experiencias de Innovación Docente de la US Esta obra se distribuye con la licencia Creative Commons 
Por lo que respecta a la secuencia de actividades programadas en este ciclo de mejora docente, debemos confesar que nos pasó lo mismo que con el mapa de contenidos, al vernos obligado a amoldarla con el propio devenir de las distintas sesiones, en forma y tiempo.

Teniendo en cuenta lo anterior, la secuencia de actividades programada, que en un principio abarcaba cuatro sesiones de dos horas cada una, acabó demandando una sesión más de dos horas.

Dicha secuencia contempla las siguientes actividades:

1. Cuestionario inicial.

El cuestionario persigue tomar conciencia de la situación de la clase, en relación con los esquemas mentales de los estudiantes y con el grado de conocimiento que manifiesta con respecto a la materia que se quiere impartir, al recoger respuestas de todos ellos en un mismo momento y permitir elaborar análisis sistemáticos (Rivero y Porlán, 2017, 77-83). La idea es proponer el desarrollo de dos cuestionarios que contemplen las misma preguntas en torno a los conocimientos que se van a impartir, uno al inicio del curso y otro al final.

En nuestro caso, hemos formulado una batería de preguntas muy concretas que los/las estudiantes deben responder de manera breve y concisa, aunque razonada, en no más de 35 min.

Las preguntas son las siguientes:

¿Qué es la arqueología?

¿Es la arqueología una actividad destructiva?

¿Cuál es el cometido principal de un arqueólogo?

Ciclos de Mejora en el Aula (2020). Experiencias de Innovación Docente de la US Esta obra se distribuye con la licencia Creative Commons 
¿Qué es y en qué consiste el registro arqueológico?

¿La estratigrafía en arqueología?

¿Qué es y en qué consiste el contexto arqueológico?

¿Enumera los distintos sistemas de registro de las entidades arqueológicas que conozca?

\section{Proyección de imágenes.}

Esta tarea ha consistido en exponer una serie de imágenes muy concretas relacionadas con cuestiones sobre lo que es y no es excavar, y con las funciones lógicas del/la arqueólogo/a. Se trata de ofrecer imágenes que contrastan entre sí, para a continuación generar preguntas en torno a ellas. El profesor orienta el camino a seguir y los/las estudiantes reflexionan en grupo, en torno a las puntualizaciones marcadas. La idea persigue, simplemente, generar un debate en torno a la arqueología y las funciones lógicas del/la arqueólogo/a, y establecer las diferencias entre lo que supone una actividad arqueológica reglada, que necesita de la aplicación de un método ordenado, lógico y preciso, y la simple búsqueda de restos del pasado.

Con estas cuestiones iniciales, simples a la vez que complejas, enmarcamos el tema, introduciendo al alumnado de lleno en el curso, le animamos a intervenir activamente en todo el proceso, y fomentamos el trabajo en grupo.

3. Proyección de videos-documentales.

En concreto se proyectan dos videos cortos. Ambos abarcan temáticas muy precisas, como son los restos arqueológicos, la excavación y el trabajo en equipo. El primero pretende abrir el debate en torno a las entidades arqueológicas, los restos arqueológicos, el patrimonio

Ciclos de Mejora en el Aula (2020). Experiencias de Innovación Docente de la US Esta obra se distribuye con la licencia Creative Commons 
arqueológico y el patrimonio cultura. El segundo muestra una excavación reglada en el que se percibe claramente el trabajo en equipo. En este caso se focaliza el debate en el trabajo grupal y en la necesidad de ser rigurosos a la hora sacar a la luz, analizar y documentar el registro arqueológico. De nuevo se generan preguntas estratégicas que los distintos grupos deben resolver.

4. Exposición de un ejemplo real de intervención arqueológica y de registro arqueológico.

Con esta nueva actividad se pretende que los/as estudiantes vean claramente el funcionamiento lógico y el día a día de una intervención arqueológica. El profesor marca un debate en torno a los conceptos registro arqueológico, estratigrafía arqueológica y contexto arqueológico. Además, anima a profundizar en la rigurosidad del método de análisis arqueológico.

Esta actividad es tan acertada y genera tal aceptación por parte de los/las estudiantes que, casi sin esperarlo, nos animamos a reconducir las dos sesiones restantes. De tal manera que la tercera sesión y la primera mitad de la cuarta se dedican al desarrollo, por parte de los distintos grupos, de un supuesto de actividad arqueológica que contemple su correspondiente registro arqueológico.

5. Elaboración de supuestos o simulacros de actividades arqueológicas por parte de los distintos grupos.

Con esta nueva actividad se pretende que los/as estudiantes pongan en funcionamiento los conocimientos asimilados, y que se genere un debate constructivo en torno a las propuestas que plantean los distintos grupos. Se consigue con ello focalizar el interés alrededor da cada una de las propuestas expresadas, sometiéndolas a un verdadero

Ciclos de Mejora en el Aula (2020). Experiencias de Innovación Docente de la US Esta obra se distribuye con la licencia Creative Commons 
escrutinio por parte de todos los/as participantes de la clase, con objeto de que se puedan mejorar, completar o matizar a partir de los comentarios emitidos. Como es lógico, el profesor también participa de ese escrutinio y matiza, aclara, proporciona o fortalece aquellos aspectos que no queden muy claros o no queden bien reflejados.

Esta actividad genera un debate tan fructífero e interesante detrás de cada sesión, que nos vemos obligado a dedicar dos horas más de las contempladas en el cronograma del ciclo de mejora, para que todos los grupos puedan exponer sus propuestas.

\section{Comentario y puesta en común final.}

Justo antes de pasar a desarrollar el cuestionario final, reservamos unos minutos de la última sesión para que los/as alumnos/as aclaren o expongan algunas dudas finales, así como para que puedan expresar sus opiniones en torno a los contenidos analizados durante el curso. Aunque en este puto se les pide que sean escuetos/as, teniendo en cuenta que en el cuestionario final tendrán que responder preguntas en relación con ese tema.

\section{Cuestionario final.}

El objetivo de este nuevo cuestionario, que reproduce las mismas preguntas que el inicial, es obtener una imagen clara del avance y evolución de los estudiantes, de manera individualizada, y del grupo en general. Asimismo, persigue poner en evidencia las fortalezas y las debilidades de la docencia impartida y de la metodología aplicada en el desarrollo del CIMA. Se introducen, además, en este nuevo cuestionario, algunas preguntas relacionadas con el docente, la calidad e idoneidad de la docencia y de los contenidos trabajados y de la metodología aplicada en el desarrollo del curso. 
La secuencia se actividades anterior se ha completado con una serie de actividades de contraste que pretendian afianzar conocimientos concretos, aclarar ciertos aspectos y reconducir la clase siempre que ha sido necesario. Las actividades de contraste han girado en torno a las propias explicaciones y orientaciones del profesor, a lecturas programadas, centradas en cuestiones y conceptos muy específicos en relación con los contenidos que se están trabajando, exposiciones cortas de ejemplos reales, etc. En ocasiones, algunas de las actividades planteadas se utilizaban como actividad de contraste de las anteriores.

\section{Desarrollo del CIMA}

El presente ciclo de mejora se programó, en un primer momento, para su desarrollo en cuatro sesiones de dos horas cada una. Si bien, al final nos vimos obligado a destinar una nueva sesión de dos horas para que pudiera acabar convenientemente.

El grupo con el que se ha puesto en marcha, lo formaban un total de 32 alumnos/as, siendo la media de asistencia a clase de unos 28 alumnos/as.

Para la organización de la clase, se han formado seis grupos, en función del número de alumnos que habían tenido algún tipo de contacto previo con la arqueología, procurando que cada uno de ellos estuviera en un grupo distinto. A estos alumnos se les pidió que en el desarrollo de las actividades en grupo no tomaran todo el protagonismo y que dejaran actuar al resto de compañeros. La composición final de los grupos fue muy interesante y ha dado mucho juego, porque de repente, y sin premeditación, se compusieron grupos multidisciplinares, formados por gente con formación muy diversa y conocimientos

Ciclos de Mejora en el Aula (2020). Experiencias de Innovación Docente de la US Esta obra se distribuye con la licencia Creative Commons 
en materias muy distintas, como arqueología, historia del arte, historia antigua, geografía, arquitectura, gestión del patrimonio, turismo, restauración, etc. Todo ello, ha dado mucho juego, y el resultado final ha sido sumamente atrayente, puesto que cada uno de ellos/as ha afrontado un mismo problemas desde una óptica muy distinta, ofreciendo soluciones múltiples, en gran parte válidas, que al final se han encaminado hacia un mismo punto en común. La experiencia, en este sentido, ha sido verdaderamente satisfactoria.

Por lo que respecta al desarrollo de CIMA, éste tuvo su inicio con las presentaciones pertinentes, que dieron paso a la formulación de una encuesta para obtener información en relación con el grado de acercamiento de cada uno de los/as alumnos/as a la arqueología. Esta encuesta nos puso en contexto y nos hizo ver la realidad de que gran parte del grupo no había tenido antes contacto alguno con la arqueología. Realidad que se vuelve a poner de manifiesto con el análisis de las respuestas expresadas por los alumnos/as en el cuestionario inicial, realizado justo después de la encuesta.

Esa situación, un tanto particular, nos obligó a reprogramar, en parte, el mapa de contenidos y preguntas, con objeto de contemplar y hacer mayor hincapié en cuestiones que ya deberían de saberse y que, en cualquier caso, eran fundamentales para el buen desarrollo de la asignatura, tales como el significado de la arqueología, utilidad, cometidos, metodología, etc. y lo mismo en torno a la labor propia del arqueólogo.

Con todo, la primera sesión sigue su trascurso programado, puesto que la propuesta para ese día ya contemplaba parte de esos contenidos. 
Tras el cuestionario inicial, la primera sesión continua con una actividad destinada a generar el debate en torno a imágenes muy concretas, a veces casi surrealistas, como mostrar un perro realizando un agujero en el suelo, junto con otras en la que se observan un arqueológico desarrollando una excavación y una persona practicando expolio; una máquina elaborando una zanja sin ningún tipo de control arqueológico y otra en la que una persona parece que está controlando los movimientos de tierra; una obra en la que se ven muchos operarios trabajando en la construcción de un edifico sin más y otra en la que se está llevando a cabo una obra pero bajo la supervisión de un arqueólogo, etc. La idea de esta batería de imágenes, que por lo general contrastan entre ellas, es generar un debate en torno a lo qué es y no es excavar, cuándo una obra requiere de control arqueológico y cuándo no, en que cosiste el control arqueológico, tipos de actividades arqueológicas, tipos de excavaciones, el contexto arqueológico, etc. El debate, que se inicia con la formulación de preguntas previas, empieza un poco tímido y son los/as alumnos/ as que tienen conocimientos en arqueologías los que primero se animan, pero con el tiempo y con la insistencia del profesor, el resto del grupo acaba sumándose a la discusión, siendo ésta tan fructífera que nos ocupa hasta el final de la clase. Por mi parte, voy aclarando algunas cuestiones que creo pertinentes, y tras la visualización de algunas de las imágenes o en otros momentos determinados, introduzco algunos contenidos que considero oportunos. Al final de la clase recomiendo una serie de lecturas que los alumnos tienen que trabajar, relacionadas con el registro arqueológico, las gestión de los materiales arqueológicos, el patrimonio arqueológico y el patrimonio cultural. Se explica por encima la sesión del día siguiente y se les comenta que en los últimos 20 min. se expondrá un caso real de excavación arqueológica. Un alumno, arqueólogo de profesión, se ofrece, de manera voluntaria, a exponer su último trabajo. Se acepta la propuesta y se le dice que tendrá que resumirla en 15 min.

Ciclos de Mejora en el Aula (2020). Experiencias de Innovación Docente de la US Esta obra se distribuye con la licencia Creative Commons 
La segunda sesión se inicia con un ligero repaso de lo visto el día anterior. Inmediatamente después procedemos a proyectar dos videos cortos que tratan diversos temas relacionados con las entidades arqueológicas, los restos arqueológicos, el patrimonio arqueológico y el patrimonio cultura, la excavación reglada, el trabajo en equipo. Tras los vídeos, los alumnos proceden a debatir a partir de problemas planteados por el profesor, primero en el seno de sus respectivos grupos, para ello tienen 35 min., y segundo en torno a las propuestas manifestadas por cada uno de los grupos. Esta última actividad se lleva a cabo en la segunda parte de la sesión y el desarrollo del debate es tan intenso que nos vemos obligados a pararlo para dejar tiempo para exponer lo ejemplos que estaban programados para el final de la clase. Por mi parte, suspendo la intervención que tenía pensada desarrollar para dejar que el alumno exponga su caso con algo más de tiempo y poder comentarlo con posterioridad. El desarrollo de esta última sesión es tan interesante que nos lleva a reprogramar las dos sesiones siguientes, de tal manera que cada grupo se anima a simular una intervención arqueológica. La idea es que enumeren de forma esquemática los pasos a seguir para abarcar de manera completa el análisis y la documentación del registro arqueológico de un yacimiento. Tienen todo un fin de semana por delante para ir perfilando y programando la actividad, que se trabajará durante la tercera sesión.

La tercera sesión se destina a que los distintos grupos trabajen en torno a sus propuestas. En mi caso me dedico a resolver cuestiones, aclarar asuntos, reorientar a algún que otro grupo que de repente se estanca en temas que no son los que estamos tratando en la asignatura, etc. De vez en cuando, llamo la atención general exponiendo ciertos contenidos que considero oportunos y que veo que no se están teniendo en cuenta. Esta sesión transcurre sin muchas incidencias, percibiéndose claramente un alto grado de animación por parte de los distintos grupos. La

Ciclos de Mejora en el Aula (2020). Experiencias de Innovación Docente de la US Esta obra se distribuye con la licencia Creative Commons 
actividad es frenética y se ve que los/as alumnos/as están disfrutando con el trabajo. Las preguntas al profesor son muy continuas en algunos casos. Los/as alumnos/as piden que parte de la próxima sesión se destine a seguir trabajando en el tema.

La cuarta sesión estaba destinada, en un primer momento, a exponer las propuestas de los distintos grupos. Si bien, y como ya hemos señalado, a petición de los/as estudiantes decidimos emplear la primera parte a seguir trabajando en las simulaciones de cada grupo.

Acabada la primera hora, comenzamos con la exposición resumida y esquemática de las distintas propuestas. Cada grupo tiene entre 10 y 15 min. para exponer su proyecto, y al final de cada exposición abrimos un debate de 10 min. Como es obvio, en esta sesión sólo no da tiempo de ver y analizar dos trabajos y de nuevo nos vemos obligado a controlar el debate por razones de tiempo.

Como ya hemos señalado en otras ocasiones, la quinta sesión no estaba programada en el CIMA, pero el propio devenir de las sesiones previas nos ha obligado a incorporarla.

En esta última sesión continuamos con la exposición y debate de las propuestas de los distintos grupos. Aunque en este caso optamos por recortar las discusiones en torno a cada propuesta a sólo 5 min., e incluso tenemos que suspender los dos últimos debates, con objeto de dejar tiempo para desarrollar el formulario final.

Todo lo anterior no es más que un ligero resumen de una CIMA que podríamos resumir como "intenso". Intenso en todos los sentidos, por interesante y gratificante y por lo animado de los debates, pero también por lo apretado 
que nos hemos visto con el tiempo. En ese sentido, es una realidad manifiesta que las actividades programadas requieren reformularse en algunos casos, sobre todo para dejar más tiempo para los debates finales, porque en algunos casos nos hemos visto obligados a paralizarlos quizás cuando más interesantes se estaban poniendo.

Por mi parte, debo confesar que si en un principio tenía ciertos reparos en la aplicación del CIMA, al final he quedado bastante satisfecho, pese a la intensidad del trabajo y pese a comprender que el programa requiere de matizaciones y reformulaciones, sobre todo en lo que a la organización de los tiempos se refiere.

Por lo que respecta a los alumnos, las valoraciones que han manifestado en las preguntas introducidas en el formulario final, relacionadas con la docencia y la metodología del curso, son igualmente positivas. En la mayoría de los casos agradecen que el profesor les haya cedido espacio y protagonismo, y que se haya aplicado una metodología basada en la resolución de problemas, con una importante carga práctica. Algunos/as alumnos/as incluso sugieren el desarrollo de más prácticas. Al mismo tiempo, resaltan el interés del trabajo en grupo, por medio del cual se fomenta la interacción entre compañeros/as y el intercambio de ideas, como se han tratado los contenidos y la necesidad de tener más tiempo para debatir sobre ellos y confrontar propuestas. Un buen número de alumnos/as aseguran que el curso se les ha hecho corto.

\section{Análisis comparativo de los cuestionarios inicial y final}

Una de los aspectos más interesantes que podemos destacar de las nuevas tendencias docentes, es la existencia de instrumentos más allá del examen para poder 
acercarnos a los esquemas mentales de los/as estudiantes y poder medir su grado de conocimiento, avance y evolución en el marco de una misma asignatura. Uno de los más efectivos, a parte del seguimiento continuado de los/ as estudiantes, a partir de su interrelación y compromiso con la clase, es, como ya hemos señalado, el cuestionario (Rivero y Porlán, 2017, 77-83).

Como hemos podido ver en la secuencia de actividades, a los/as alumnos/as se les pide que cumplimenten dos formularios, uno al principio del curso y otro al final. El formulario, que recoge las mismas preguntas en relación con el contenido del curso, se debe desarrollar en un espacio de tiempo no muy extenso, y se les pide a los/ as estudiantes que expresen libremente lo que realmente piensan sobre lo que se les está preguntando, y que se alejen del intento de emitir respuestas eruditas que pudieran resultar forzadas.

En el segundo cuestionario se ha introducido, además, una serie de preguntas relacionadas con la metodología aplicada por el profesor en la impartición de la docencia, grado de satisfacción con los contenidos expresados y con el propio docente, etc. El objetivo de estas nuevas preguntas es generar una imagen de la docencia y de la metodología aplicada, para poder evaluar la actitud del docente, la calidad de la docencia impartida e idoneidad de los contenidos y la eficacia del ciclo de mejora y de las actividades programadas.

Una vez desarrollado el segundo cuestionario, para controlar y medir las respuestas emitidas por el grupo, hemos recurrido a las escaleras de aprendizaje, que nos permiten agrupar las respuestas en función del mayor o menor grado de conocimiento expresado (Rivero y Porlán, 2017, 88-91). Estas escaleras, permiten, al mismo tiempo, obtener una visión clara de todo lo que está aconteciendo, 
de los conocimientos imperantes en la clase al inicio del curso, de los obstáculos superados y no superados por la mayoría de los estudiantes, al final, la evolución de cada estudiante de manera individual y la idoneidad de las actividades de contrastes utilizadas (Rivero y Porlán, 2017, 88-91).

En el diseño de nuestra escalera de aprendizaje se ha creado la siguiente secuencia en base al grado de acierto de las respuestas:

Primer escalón de conocimiento: No responde o la respuesta emitida no concuerda o no tiene relación con la realidad expresada en la pregunta.

Segundo escalón de conocimiento: La respuesta emitida contiene ideas muy generales o básicas sobre la cuestión planteada, a veces poco acertadas.

Tercer escalón: La respuesta contempla conocimientos más acertados y extensos sobre la realidad preguntada.

Cuarto escalón: La respuesta es acertada y ofrece conocimientos sólidos y certeros en relación con la materia.

De los 32 alumnos/as que forman el grupo, sólo 25 completan el formulario.

Para el análisis comparativo de las respuestas, se han ordenados y reagrupados los distintos cuestionarios en base a las similitudes de cada una de las respuestas expresadas, se han calculado los porcentajes y se han representado en los peldaños que corresponda de la escalera según su grado de acierto. Finalmente, para obtener una visión más clara de lo acontecido, se contrastan las escaleras de conocimiento resultado del análisis de los formularios inicial y final:

Ciclos de Mejora en el Aula (2020). Experiencias de Innovación Docente de la US Esta obra se distribuye con la licencia Creative Commons 
Pregunta 1. ¿Qué es la arqueología?

Pregunta 1

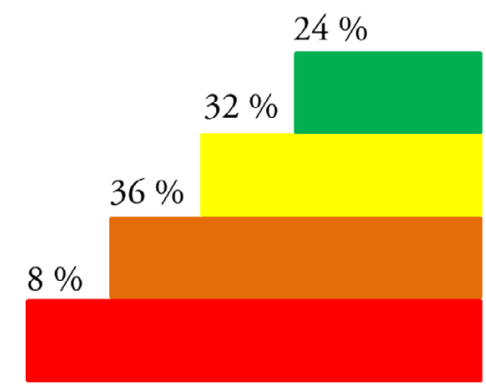

Cuestionario inicial

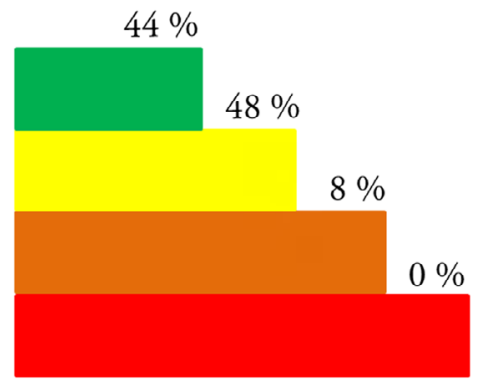

Cuestionario final

Pregunta 2. ¿Es la arqueología una actividad destructiva? Pregunta 2

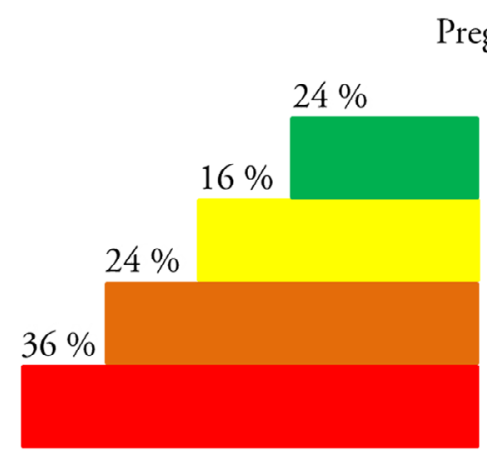

Cuestionario inicial

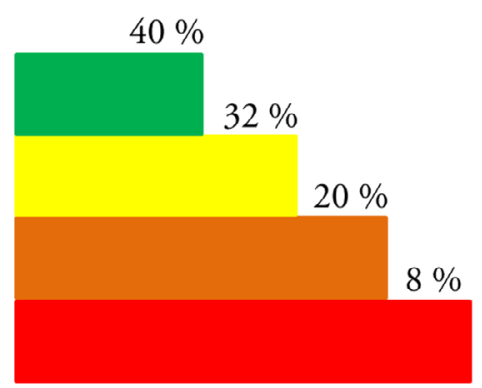

Cuestionario final

Pregunta 3. ¿Cuál es el cometido principal de un arqueólogo?

Pregunta 3

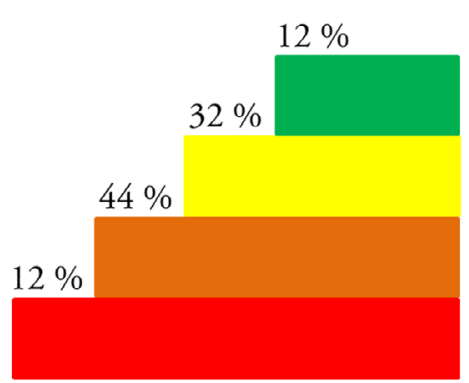

Cuestionario inicial

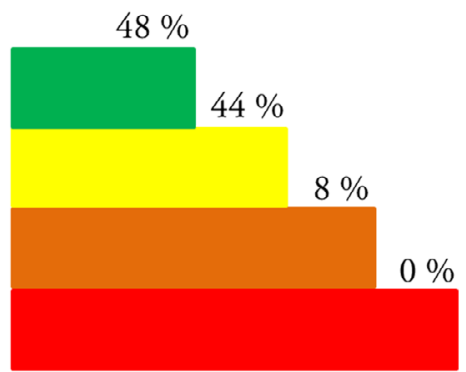

Cuestionario final

Ciclos de Mejora en el Aula (2020). Experiencias de Innovación Docente de la US Esta obra se distribuye con la licencia Creative Commons Reconocimiento-NoComercial-SinObraDerivada Internacional (CC BY-NC-ND 4.0.) 
Pregunta 4. ¿Qué es y en qué consiste el registro arqueológico?

\section{Pregunta 4}

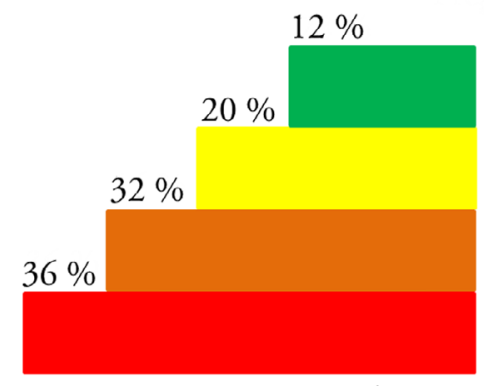

Cuestionario inicial

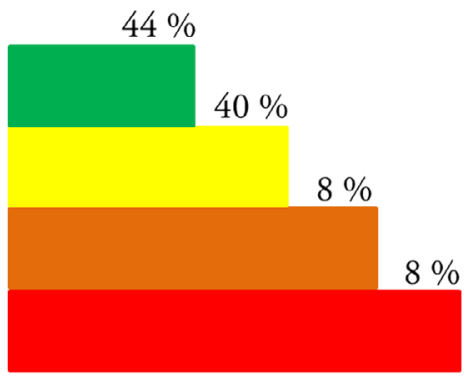

Cuestionario final

Pregunta 5. ¿La estratigrafía en arqueología?

Pregunta 5

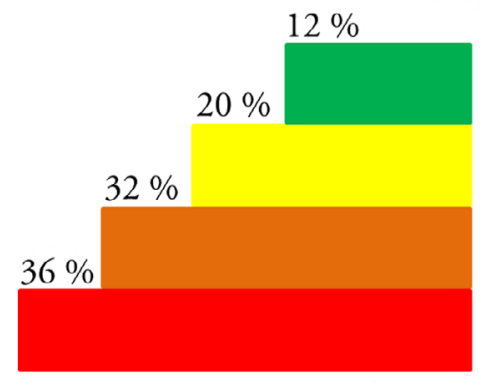

Cuestionario inicial

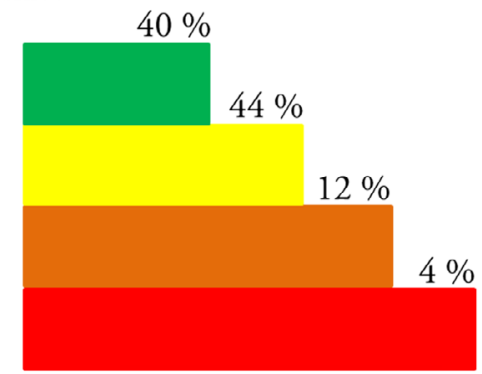

Cuestionario final

Pregunta 6. ¿Qué es y en qué consiste el contexto arqueológico?

\section{Pregunta 6}

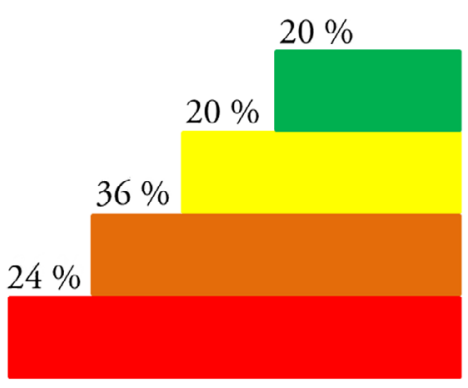

Cuestionario inicial

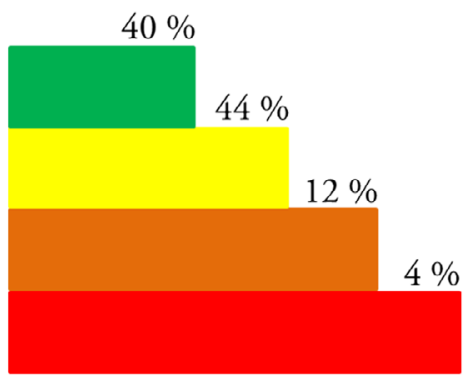

Cuestionario final

Ciclos de Mejora en el Aula (2020). Experiencias de Innovación Docente de la US Esta obra se distribuye con la licencia Creative Commons Reconocimiento-NoComercial-SinObraDerivada Internacional (CC BY-NC-ND 4.0.) 
Pregunta 7. ¿Enumera los distintos sistemas de registro de las entidades arqueológicas que conozca?

Pregunta 7

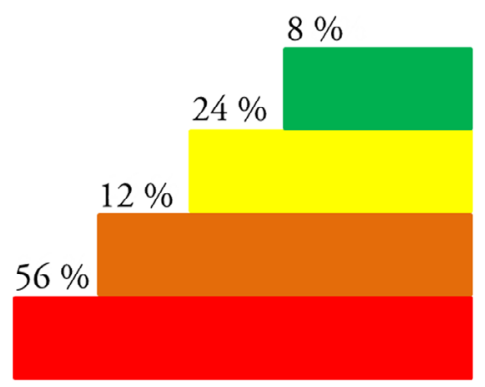

Cuestionario inicial

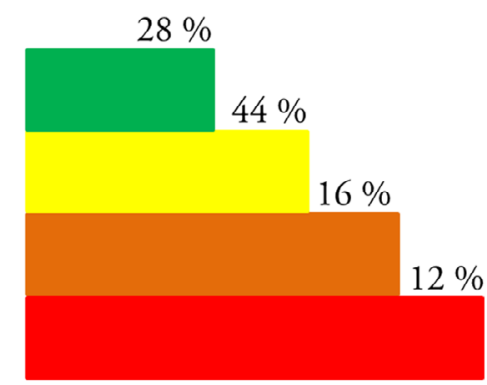

Cuestionario final

\section{Evolución del aprendizaje del grupo a partir de los formularios y a partir de los datos que arrojan las anteriores escaleras de aprendizaje}

Los datos anteriores expresan un cambio y una mejora generalizada muy significativo, sobre todo si tenemos en cuenta los obstáculos que representaba que la mayor parte del alumnado matriculado en la asignatura no hubiera tenido antes ningún tipo de contacto con la arqueología.

Ese alejamiento de gran parte de los estudiantes de la temática a abordar, justifica claramente que algunas de las respuestas emitidas en el formulario inicial, en torno a cuestiones tan singulares como qué es la arqueología o cuál es la labor del arqueólogo, entre otras, no tuviera un indice de acierto mucho más amplio.

Por lo que respecta a las respuestas del formulario final, sorprende que algunos estudiantes hayan repetido respuesta a preguntas tan notorias como aquella que gira en torno a la idea de si la arqueología implica algún tipo de destrucción en su desarrollo, emitiendo una respuesta negativa y una justificación muy alejada de la realidad. Es Ciclos de Mejora en el Aula (2020). Experiencias de Innovación Docente de la US 
significativo, además, porque después que revisar el formulario inicial, se hizo mucho hincapié y se profundizó bastante en estos aspectos. Sobre todo para remarcar que el hecho de que la excavación arqueológica implique la retirada irreversible de los distintos estratos, lleva pareja la destrucción de los mismos, de ahí la necesidad de la puesta en marcha de un control absoluto de la actividad, y de un análisis, registro y documentación, meticuloso, ordenado y continuo de la información.

En contraste con lo anterior, también debemos señalar la precisión de algunas respuestas emitidas por otros/as alumnos/as que en el formulario inicial habían dado una respuesta previa poco consistente.

Junto a los ejemplos anteriores, debemos remarcar la evolución de aquellos/as estudiantes que tenían cierta relación previa con la arqueología. En algunos/as de ellos/ as la evolución ha sido menos notorias, sobre todo en los/ as que al principio demostraron tener una amplia experiencia y unos conocimientos sólidos. Estos/as alumnos/ as, que se han implicado profundamente en el curso, ha ayudado de manera muy notable a su buen desarrollo, exponiendo y contrastando algunos ejemplos y experiencias personales, así como ayudando a los componentes de sus respectivos grupos.

En lo que a la evaluación final se refiere, debemos decir que, junto a los cuestionarios, la evaluación del grupo se ha completado con el seguimiento diario de cada uno de los/as alumnos/as, comprobando y observando su actitud frente a los problemas y las cuestiones planteadas, examinando sus aportaciones y respuestas, así como analizando la resolución de las actividades programadas. Todo ello ha servido, igualmente, para poder evaluar la calidad de la docencia impartida y del método didáctico aplicado,

Ciclos de Mejora en el Aula (2020). Experiencias de Innovación Docente de la US Esta obra se distribuye con la licencia Creative Commons 
en base a las notas recogidas en el diario del profesor y a encuestas programadas en determinados momentos (siguiendo las orientaciones de Rivero y Porlán, 2017, 86-88), que se suman a las preguntas introducidas en el formulario final en relación con esos temas.

En cualquier caso, creo que el resultado ha sido muy satisfactorio para todos, especialmente para mí como docente, y que la evolución positiva del grupo ha sido más que evidente. Por lo que respecta a la metodología puesta en marcha en el curso, las respuestas de las preguntas contenidas en el formulario final, ponen de manifiesto cierto grado de satisfacción con respecto al docente, los conocimientos impartidos, la dinámica de la clase, las actividades, etc. Aun así, es obvio que se deben introducir cambios que ayuden a limar, definir y precisar más algunos aspectos.

\section{Consideraciones finales}

Para finalizar, sólo me queda señalar la buena impresión que me ha causado el cambio radical de metodología a la hora de impartir la docencia, que dicho sea de paso, me generaba, en un principio, cierta ansiedad. Observar que los/as alumnos/as se implican mucho más y participan de manera más activa en clase, ha sido realmente sorprendente. Comprobar que yo mismo tenía que estar más activo en las clases, atendiendo a las dudas y preguntas del grupo, o que la simple formulación de una buena pregunta en torno a un concepto clave ayuda a profundizar en numerosas partes y contenidos distintos de la asignatura y a que los/as alumnos/as se planteen nuevas cuestiones o se encaminen ellos/as mismos/as a otros conceptos implícitos en aquél para intentar desgranarlos, ha supuesto, igualmente, una sorpresa y una gran satisfacción.

Ciclos de Mejora en el Aula (2020). Experiencias de Innovación Docente de la US Esta obra se distribuye con la licencia Creative Commons 
En resumen, podría decir que desarrollar y poder aplicar el CIMA aquí expuesto, ha supuesto un importante esfuerzo y un verdadero reto, que al final ha proporcionado una grata recompensa. Simplemente con ver que hay algo más allá de la simple clase magistral, que el/la estudiante debe convertirse en un actor/actriz mucho más activo/a, involucrado/a y comprometido/a en el proceso de enseñanza-aprendizaje, o que el propio docente debe autoevaluarse y evaluar sus formas, modos y métodos que aplica, pone de relieve la necesidad de adentrarse en este tipo de experiencia.

Ciclos de Mejora en el Aula (2020). Experiencias de Innovación Docente de la US Esta obra se distribuye con la licencia Creative Commons 
Palabras clave: Arqueología, Documentación y análisis del registro arqueológico, Máster en arqueología, docencia universitaria, experimentación docente universitaria.

Keywords: archeology, Documentation and analysis of the archaeological record, Master in archeology, University teaching, University teaching experimentation.

\section{Bibliografía}

Bain, K. (2007). Lo que hacen los mejores profesores universitarios. Valencia: Universidad de Valencia.

De Alba, N. y Porlán, R. (2017). La metodología de enseñanza. En R. Porlán (Coord.), Enseñanza universitaria. Cómo mejorarla (pp. 37-53). Madrid: Morata.

Finkel, D. (2008). Dar clase con la boca cerrada. Valencia: Universidad de Valencia.

Porlán, R. (Coord.) (2017). Enseñanza universitaria: Cómo mejorarla. Madrid: Morata.

Rivero, A. y Porlán, R. (2017). La evaluación en la enseñanza universitaria. En R. Porlán (Coord.), Enseñanza universitaria. Cómo mejorarla (pp. 73-91). Madrid: Morata.

Ciclos de Mejora en el Aula (2020). Experiencias de Innovación Docente de la US Esta obra se distribuye con la licencia Creative Commons 